\title{
CAPÍTULO 40: BOAS PRÁTICAS NA FABRICAÇÃO DE BOMBONS ARTESANAIS E PONTOS CRÍTICOS DE CONTROLE
}

\section{CHAPTER 40: GOOD PRACTICES IN THE MANUFACTURE OF HANDMADE CHOCOLATE AND CRITICAL CONTROL POINTS}

\author{
Ângela Christina Conte Theodoro'; Ana Lúcia Lima²; Juliana Rodrigues Donadon ${ }^{3}$ Danielle Bogo ${ }^{4}$; \\ Raquel Pires Campos ${ }^{5}$
}

\begin{abstract}
Resumo
O chocolate apresenta grande consumo e na forma de bombons tem importante aceitação pelo consumidor e influência em sua apresentação. O objetivo do trabalho foi avaliar os possíveis perigos na fabricação de bombons artesanais e identificar os pontos críticos de controle para segurança e qualidade durante a fabricação, visando oferecer um produto com qualidade e segurança para o consumidor. Foi realizada uma observação in loco da produção de bombons caseiros no município de Campo Grande - MS, caracterizando um estudo de caso. O estabelecimento de produção artesanal de bombons apresentou 54,79 \% dos itens em conformidades na lista de verificação das Boas Práticas de Fabricação. Foram identificados os seguintes Pontos Críticos de Controle: desenformação, embalagem, refrigeração, armazenamento e transporte. Portanto, é necessária a padronização do processo de fabricação artesanal e um adequado controle higiênico-sanitário tanto do local de produção, quanto dos manipuladores e a forma que os bombons serão comercializados.
\end{abstract}

Palavras-Chave: chocolate, qualidade, segurança.

\begin{abstract}
Chocolate is widely consumed and in the form of handmade chocolates it has important acceptance by the consumer and influences its presentation. The objective of the work was to evaluate the possible dangers in the manufacture of handmade chocolates and to identify the critical points of control for safety and quality during manufacture, aiming to offer a product with quality and safety to the consumer. An on-site observation of the production of homemade chocolates was carried out in the municipaly of Campo Grande - MS, featuring a case study. The establishment of production of chocolates handmade presented $54.79 \%$ of the items in conformity in the checklist of Good Manufacturing Practices. The following Critical Control Points were identified: removal from the mold, packaging, refrigeration, storage and transportation. Therefore, it is necessary to standardize the artisanal manufacturing process and adequate hygienic-sanitary control both at the place of production anda the handlers and the way that the chocolates will be marketed.
\end{abstract}

Keywords: chocolate, quality, safety.

\footnotetext{
${ }^{1}$ Tecnóloga em Alimentos, UFMS, angelachristiina@gmail.com

2 Tecnóloga em Alimentos, UFMS, analulima2010@ hotmail.com

${ }^{3}$ Doutora de Saúde e Desenvolvimento na Região Centro-Oeste, UFMS, daniellebogo@gmail.com

${ }^{4}$ Doutora em Agronomia, UFMS, julianadonadon@yahoo.com.br

${ }^{5}$ Doutora em Agronomia, UFMS, raquel.campos@ufms.br
} 


\section{Introdução}

O bombom é originário da Espanha e logo se difundiu pela Europa, com diversas simbologias, sendo consumido principalmente como um alimento divino (BATISTA, 2008). Cristóvão Colombo foi quem trouxe as sementes de cacau para Europa (DIOGO et al., 2015) e durante muitos anos o chocolate foi consumido como alimento quente, somente após a revolução industrial passou a ser popular e consumido em forma de tabletes, ganhando assim, consumo nas diferentes classes sociais (BATISTA, 2008).

O chocolate é definido como uma mistura de derivados de cacau (Theobroma cacao L.), massa, pasta ou licor de cacau, cacau em pó e/ou manteiga de cacau, de forma e consistência variada, com adição de outros ingredientes, contendo no mínimo $25 \%$ (g. $100 \mathrm{~g}^{-1}$ ) de sólidos totais de cacau, podendo conter recheio e/ou cobertura (BRASIL, 2005; LUBAS et al., 2016).

O bombom de chocolate é um produto constituído de chocolate ou por um núcleo formado de recheios diversos como pedaços de frutas in natura ou secas, oleaginosas, leite, licores, cremes, entre outros, recobertos por uma camada de chocolate ou glacê (DIOGO et al., 2015).

O processo de fabricação de bombons artesanais é feito a partir do chocolate industrial, que é obtido da mistura de cacau, açúcar e leite em pó, denominada massa de chocolate. É elaborado com diversas variações dependendo do tipo de bombom que se quer produzir. Os produtos elaborados em casa, sem equipamentos próprios tendem a ter maior chance de contaminação, pois são produzidos das mais diversas formas e lugares, podendo haver ineficiência dos procedimentos de higiene pessoal e de sanitização das superfícies de manipulação, bem como dos vasilhames a serem utilizados (BATISTA, 2008).

Para estes alimentos destinados ao consumo humano, torna-se necessária a fiscalização de órgãos competentes, padronização do procedimentos de higiene operacional e implementação de Boas Práticas de Fabricação (BRASIL, 2013). Com a crescente preocupação referente a qualidade e segurança dos produtos comercializados e consumidos, tem-se incentivado o desenvolvimento e a criação de regulamentações e ferramentas como forma de garantir ao consumidor de produtos artesanais, a mesma qualidade dos produtos produzidos de forma industrial (TEJEDA, 2012).

Para tanto, foi implantada a RDC n 49 de 31 de outubro de 2013 que apresenta diretrizes de proteção da produção de alimentos em pequena escala que convergem com ações da Política Nacional de Segurança Alimentar e Nutricional (PNSAN) que visam a valorização das culturas alimentares e o estímulo a circuitos regionais de produção, distribuição e consumo de alimentos (CINTRÃO, 2017). 
O uso de ferramentas como as Boas Práticas de Manipulação (BPM) e Procedimentos Operacionais Padronizados (POPs) tornam os produtos aptos ao consumo humano e satisfação dos clientes com normas e procedimentos para atingir um determinado padrão de qualidade de um produto ou de um serviço na área de alimentos (ROSA, 2015).

É necessário a avaliação das Boas Práticas de Fabricação nas entidades que produzem alimentos, tensionando assim a melhoria das condições de higiene e saúde que abrangem a fabricação dos produtos, de modo que se obtenha um diagnóstico da situação, propondo ajustes e/ou aperfeiçoamento (DE OLIVEIRA et al., 2020).

A fabricação dos bombons caseiros tem um caráter puramente artesanal, podendo originar um produto sem garantia de segurança microbiológica, com consequências danosas aos consumidores. Segundo a Organização Pan-Americana de Saúde (OPAS, 2011), as BPF constituem um conjunto de princípios e regras para o correto manuseio do alimento abrangendo desde as matérias-primas até o produto final.

A implantação do sistema de Análise de Perigos e Pontos Críticos de Controle (APPCC) na fabricação de bombom artesanal atenderá as exigências dos consumidores, cada vez mais preocupados em saber como foram produzidos seus alimentos. O sistema APPCC é uma das ferramentas de qualidade, prevista em legislação, com a finalidade de prevenir e garantir a inocuidade e segurança dos alimentos por meio do controle de perigos. A implementação dessa ferramenta deve ser elaborada com base nas características do estabelecimento. Associado aos programas de BPF e aos POPs, são ferramentas essenciais para a gestão da qualidade nos locais produtores de alimentos (SALGADO et al., 2020).

O sistema é baseado em etapas inerentes ao processamento industrial dos alimentos, desde a obtenção da matéria-prima até o consumo e fundamenta-se em identificar os perigos potenciais à saúde do consumidor e medidas de controle de condições que possam gerar riscos. Os perigos analisados podem ser físicos, químicos e/ou biológicos (RIBEIRO-FURTINI; ABREU, 2006). Dessa forma, o objetivo deste trabalho foi avaliar os pré-requisitos de Boas Práticas de Fabricação do bombom artesanal e identificar os Pontos Críticos de Controle para segurança e qualidade durante a fabricação.

\section{Material e Métodos}

Foi utilizada uma abordagem qualitativa na modalidade de estudo de caso (GIL, 2008). Um diagnóstico do local e do processo de produção de bombons foi realizado com base na estrita observação in loco da produção artesanal numa residência na cidade de Campo Grande, Mato Grosso do Sul, entre os meses de março a junho de 2017. De maneira mais detalhada 
foram avaliados os seguintes itens: edificação e instalações, equipamentos, móveis e utensílios, manipuladores, produção e transporte do alimento e documentação. O instrumento utilizado foi o checklist contido na RDC n. 275 de 21 de outubro de 2002, como método de identificar a aplicação dos pré-requisitos: Boas Práticas de Fabricação e Procedimento Padrão de Higiene Operacional. A porcentagem em conformidade foi classificada de acordo com a legislação: GRUPO $1-76$ a $100 \%$ de atendimento aos itens; GRUPO 2 - 51 a $75 \%$ de atendimento aos itens; GRUPO 3 - 0 a $50 \%$ de atendimento aos itens (BRASIL, 2002).

Acompanhou-se a rotina de produção, armazenamento e expedição sem intervenção. Um diagrama de blocos foi elaborado com todas as etapas de produção. Os Pontos Críticos de Controle foram apontados por meio da observação do processamento dos bombons e uso de árvore decisória conforme a ocorrência dos perigos físicos, químicos e microbiológicos.

\section{Resultados e Discussão}

\section{Processo de produção e avaliação higiênico-sanitária}

O processo de produção é manual e artesanal, e os utensílios e equipamentos são de uso comum com os demais moradores da residência. A formulação básica do bombom elaborado tem como insumos o chocolate em barra, leite condensado, creme de leite e coco ralado. Os resultados da avaliação das condições higiênico-sanitárias da produção de bombons artesanais alertam para a necessidade de implementação das Boas Práticas de Fabricação, pois foram observadas falhas nos requisitos analisados (Tabela 1).

\section{Classificação segundo as BPF}

Quanto as conformidades nos itens da lista de verificação das Boas Práticas de Fabricação em estabelecimentos produtores/industrializadores de alimentos, pelo valor médio das conformidades de 54,79\% este estabelecimento pertence ao GRUPO 2 - 51 a $75 \%$ de atendimento dos itens avaliados (BRASIL, 2002).

\section{Conformidades das condições de edificação e instalações}

Quanto ao quesito edificação e instalações obteve-se média de 67,67 \% de conformidade, onde foi observado que o acesso ao local de preparo é de uso comum a outros usos, as janelas e portas não tem proteção contra insetos e animais domésticos, assim como a falta de proteção adequada nas luminárias.

As paredes eram todas revestidas de material impermeável e de fácil limpeza, assim como o piso que estava em boas condições de conservação e era de cor clara. Embora estes aspectos não representem riscos imediatos à qualidade dos produtos elaborados, podem levar a um conjunto de comportamentos que causam problemas de qualidade. Entre os graves 
problemas notados pode-se destacar: a falta de lavatórios específicos para a higienização das mãos e descarte de resíduos inadequados.

Tabela 1. Avaliação da conformidade dos itens verificados no checklist das Boas Práticas de Fabricação na produção de bombons artesanais em Campo Grande - MS.

\begin{tabular}{|c|c|}
\hline Itens de Verificação & Conformidade (\%) \\
\hline 1. Edificação e instalações & 67,67 \\
\hline 1.1 Área externa & 50 \\
\hline 1.2 Acesso & 0 \\
\hline 1.3 Área interna & 100 \\
\hline 1.4 Piso & 100 \\
\hline 1.5 Tetos & 100 \\
\hline 1.6 Paredes e divisórias & 66,6 \\
\hline 1.7 Porta & 66,6 \\
\hline 1.8 Janelas e outras aberturas & 66,6 \\
\hline 1.9 Escadas, elevadores de serviço, estruturas auxiliares & NA \\
\hline 1.10 Instalações sanitárias e vestiários para os manipuladores & 19,9 \\
\hline 1.11 Instalações sanitárias para os visitantes e outros & 100 \\
\hline 1.12 Lavatórios na área de produção & 100 \\
\hline 1.13 Iluminação e instalações elétricas & 66,6 \\
\hline 1.14 Ventilação e climatização & 50 \\
\hline 1.15 Higienização das instalações & 44,4 \\
\hline 1.16 Controle integrado de vetores e pragas urbanas & 66,6 \\
\hline 1.17 Abastecimento de água & 38,46 \\
\hline 1.18 Manejo dos resíduos & 100 \\
\hline 1.19 Esgoto sanitário & 100 \\
\hline 1.20 Leiaute & 50 \\
\hline 2 Equipamentos, móveis e utensílios & 76,35 \\
\hline 2.1 Equipamentos & 50 \\
\hline 2.2 Móveis (mesas, bancadas, vitrines, estantes) & 100 \\
\hline 2.3 Utensílios & 100 \\
\hline $\begin{array}{l}2.4 \text { Higienização dos equipamentos e maquinários, móveis e } \\
\text { utensílios }\end{array}$ & 55,5 \\
\hline 3 Manipuladores & 41,65 \\
\hline 3.1 Vestuários & 33,3 \\
\hline 3.2 Hábitos higiênicos & 66,6 \\
\hline 3.3 Estado de saúde & 0 \\
\hline 3.4 Programa de controle de saúde & 0 \\
\hline 3.5 Equipamentos de proteção individual & 0 \\
\hline 3.6 Programa de capacitação dos manipuladores e supervisão & 0 \\
\hline 4 Produção e transporte do alimento & 26,24 \\
\hline 4.1 Matéria-prima, ingredientes e embalagens & 9 \\
\hline 4.2 Fluxo de produção & 0 \\
\hline 4.3 Rotulagem e armazenamento do produto final & 22,22 \\
\hline 4.4 Controle de qualidade do produto final & 0 \\
\hline 4.5 Transporte do produto final & 0 \\
\hline 5 Documentação & $\mathbf{0}$ \\
\hline 5.1 Manual de Boas Práticas de Fabricação & 0 \\
\hline 5.2 Procedimentos Operacionais Padronizados & 0 \\
\hline Média geral de conformidades & $\mathbf{5 4 , 7 9}$ \\
\hline
\end{tabular}




\section{Conformidade das condições dos equipamentos, móveis e utensílios}

Referente aos equipamentos, obteve-se média de $50 \%$ de conformidade. Móveis como mesas, bancadas, vitrines e estantes e os utensílios estavam $100 \%$ em conformidade segundo a RDC 275 (BRASIL, 2002). Porém, no quesito higienização desses itens, o índice de conformidade reduziu para 55,5\%.

\section{Conformidade das condições dos manipuladores}

Referente aos manipuladores, observou-se ausência de calçados e vestimentas adequados para a produção de alimentos, ausência de registros do estado de saúde dos funcionários e hábitos higiênicos incorretos devido à falta de local adequado para lavagem das mãos. A higienização correta e frequentemente das mãos e a higiene pessoal são hábitos essenciais para a manutenção da qualidade dos alimentos (LOVATTI, 2004). Notou-se também que não há programa de controle de saúde dos manipuladores, falta do equipamento de proteção individual e um programa de capacitação dos manipuladores e supervisão.

\section{Conformidades das condições da produção e transporte}

Em relação à produção e transporte do alimento obteve-se $26,24 \%$ de conformidade (Tabela 1). A prática de armazenamento foi uma das principais falhas das produções analisadas, uma vez que pode ser determinante para a qualidade do produto final pois, no local os produtos eram armazenados em mesmo refrigerador de uso comum com os demais moradores da residência. Sousa et al. (2010), também citaram o armazenamento como uma das principais falhas observadas durante a produção de bombons de chocolate com recheio de frutas.

\section{Conformidades da documentação}

Constatou-se que o estabelecimento não possuía Manual de Boas Práticas (BPF), nem os Procedimentos Operacionais Padronizados (POPs) e nem conhecimento a respeito do assunto, o que resultou em $100 \%$ de inconformidade para o item documentação (Tabela 1). O resultado encontrado é similar ao de Sousa et al. (2010), que também constataram que os fabricantes de bombom com recheio de frutas não possuíam o Manual de Boas Práticas de Fabricação e nem os Procedimentos Operacionais Padronizados.

Estes têm importância fundamental em locais produtores de alimentos, pois descrevem as operações realizadas, como requisitos sanitários, manutenção e higienização das instalações, equipamentos e utensílios, o controle da água de abastecimento, o controle integrado de vetores e pragas urbanas, controle da higiene e saúde dos manipuladores, tendo em vista a garantia da qualidade do produto final (SILVA JUNIOR, 2002). Os PPHO são considerados críticos na cadeia produtiva de alimentos. Para tal, recomenda-se a adoção de programas de monitoramento, registros, ações de correção e a aplicação constante do checklist (RIBEIRO- 
FURTINI; ABREU, 2006) a fim de evitar possíveis problemas.

A falta de conscientização sobre as Boas Práticas de Fabricação, a falta de controle da temperatura do ambiente de armazenamento do chocolate e formulação das trufas com alto teor de umidade foram as principais causas de contaminação por mofo em trufas de chocolate constatados numa fábrica na região metropolitana do Recife (CORREA; DE OLIVEIRA, 2017).

Desta forma a implementação das BPFs e POP's favorecem um melhor desempenho na produção de alimentos, garantindo segurança e qualidade dos produtos (BRASIL, 1997) e são considerados pré-requisitos do APPCC (BRASIL, 1998).

\section{Processo produtivo e PCC}

O processo produtivo e pontos críticos de controle foram descritos em diagrama de blocos (Figura 1). No processo de produção, foram introduzidos pontos de controle às etapas de armazenamento, transporte, resfriamento, desenformar e embalar. Estes pontos passaram a ser controlados, pois sabe-se que o chocolate não pode ser manuseado em ambiente com temperatura elevadas ou muito baixas como também, deve ser manuseado em ambiente com umidade relativa controlada.

O espaço disponível para produção, armazenamento de matérias-primas, insumos e produtos é limitado e de uso comum com outras atividades do manipulador, onde a produção é realizada em uma cozinha doméstica de uso comum entre os moradores da residência, sendo inviável um fluxo de produção ordenado. A falta de qualificação e treinamento para a produção de bombons pode ocasionar produtos sem garantia de segurança microbiológica, com sérias consequências ao produto final e também ao consumidor (BATISTA, 2008).

A Análise de Perigos e Pontos Críticos de Controle tem grande importância na indústria de alimentos pois, possibilita a garantia de produtos sem quaisquer contaminantes. A análise é realizada durante a fabricação, permitindo o controle da transformação da matériaprima em produto final. Esse controle rigoroso proporciona maior qualidade e segurança, redução de perdas e retrabalho no processo produtivo (QUINTINO; RODOLPHO, 2018).

No processamento do bombom as etapas que requerem atenção são: resfriamento, desenformação, embalagem, armazenamento e transporte, conforme os Quadros 1, 2, 3, respectivamente. 
Figura 1. Diagrama de blocos da produção de bombons artesanais em Campo Grande - MS.

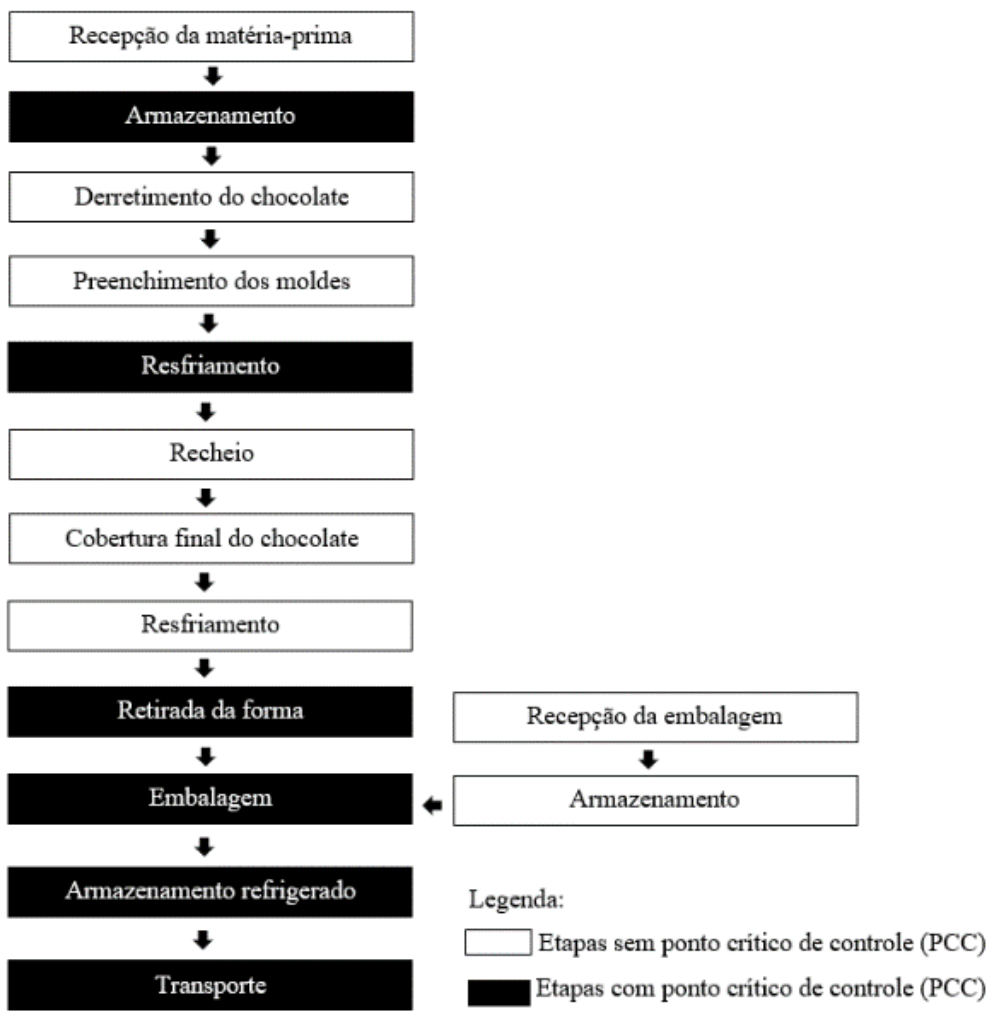

Fonte: Própria (2020).

\section{Resfriamento}

Quadro 1. Pontos Críticos de Controle para etapa de resfriamento da produção de bombons artesanais em Campo Grande - MS.

\begin{tabular}{|c|c|}
\hline $\begin{array}{l}\text { Perigo para qualidade e } \\
\text { segurança }\end{array}$ & $\begin{array}{l}\text { Físico: temperatura inadequada }{ }^{\mathrm{a}} \\
\text { Biológicos: microrganismos patogênicos }{ }^{\mathrm{a}}\end{array}$ \\
\hline Medidas preventivas & $\begin{array}{l}\text { Equipamento para uso exclusivo para armazenar o produto }{ }^{b} \\
\text { Controle de tempo e temperatura de refrigeração com uso de medidores } \\
\text { de temperatura }{ }^{b} \\
\text { Resfriamento rápido }^{b}\end{array}$ \\
\hline Risco & Alto $^{\text {a }}$ \\
\hline Severidade & Alto $^{\text {a }}$ \\
\hline Limite crítico & Estocagem $\leq 7^{\circ} \mathrm{C}^{\mathrm{b}}$ \\
\hline Monitoramento & $\begin{array}{l}\text { O quê? Temperatura adequada e tempo de resfriamento }{ }^{\text {a }} \\
\text { Como? Medição e registro de tempo e temperatura de resfriamento }{ }^{\text {a }} \\
\text { Quando? Controle diário de estoque e registrador contínuo de } \\
\text { temperatura a } \\
\text { Quem? Funcionário responsável pelo processamento do bombom }{ }^{\text {a }}\end{array}$ \\
\hline Ação corretiva & Controle de tempo e temperatura de resfriamento $\left(4^{\circ} \mathrm{C}-5^{\circ} \mathrm{C}\right)^{\mathrm{a}}$ \\
\hline Verificação & Calibração dos instrumentos de medição de temperatura. Supervisão ${ }^{a}$ \\
\hline Registro & $\begin{array}{l}\text { Registrar planilhas de controle de temperatura de resfriamento com } \\
\text { assinatura do responsável e data de recebimento }{ }^{\text {a }}\end{array}$ \\
\hline
\end{tabular}


Para a fabricação dos bombons o resfriamento ocorre no momento da formação de "casquinha" de chocolate nos moldes preenchidos de chocolate derretido, em várias etapas para haver engrossamento deste revestimento. Em escala industrial, as formas de bombom passam pelo túnel de resfriamento para endurecer e atingir as condições ideias para o desenforme (PINTO; THEODORO, 2017).

\section{Desenforme e embalagem}

Quadro 2. Pontos Críticos de Controle para etapa de desenforme e embalagem da produção de bombons artesanais em Campo Grande - MS.

\begin{tabular}{|c|c|}
\hline $\begin{array}{l}\text { Perigo para qualidade e } \\
\text { segurança }\end{array}$ & Recontaminação e/ou multiplicação de microrganismos patogênicos a \\
\hline Medidas preventivas & $\begin{array}{l}\text { Uso de EPI adequado na etapa de retirada do bombom dos moldes }{ }^{a} \\
\text { Armazenamento adequado das embalagens }{ }^{a} \\
\text { Higiene adequada do manipulador }^{\mathrm{b}} \\
\text { Controle de temperatura do ambiente }^{\mathrm{b}}\end{array}$ \\
\hline Risco & Baixo $^{a}$ \\
\hline Severidade & Alto $^{\text {a }}$ \\
\hline Limite crítico & $\begin{array}{l}\text { Coliformes a } 45^{\circ} \mathrm{C}: 10 \mathrm{UFC} / \mathrm{cm}^{2} \text { plástico }^{\mathrm{d}} \\
\text { Salmonella sp: ausência em } 25 \mathrm{~g} \text { de amostra } \\
\text { Temperatura ambiente } \leq 15^{\circ} \mathrm{C}^{\mathrm{b}}\end{array}$ \\
\hline Monitoramento & $\begin{array}{l}\text { O quê? Controle de temperatura ambiente }{ }^{\mathrm{a}} \\
\text { Como? Observação visual do laudo e instrumento de controle } \\
\text { (termômetro) }^{\text {a }} \\
\text { Quando? Durante a retirada do molde e embalagem }^{\text {a }} \\
\text { Quem? Funcionário responsável pelo processo } \\
\end{array}$ \\
\hline Ação corretiva & Ajustar condições de trabalho $^{\text {a }}$ \\
\hline Verificação & Supervisão ${ }^{a}$ \\
\hline Registro & $\begin{array}{l}\text { Registrar os laudos recebidos e as análises de verificação com } \\
\text { assinatura do responsável e data de recebimento }{ }^{\text {a }}\end{array}$ \\
\hline
\end{tabular}

Fonte: Própria (2020) ${ }^{\mathrm{a}}$, adaptado de SEBRAE (2000) ${ }^{\mathrm{b}}$, adaptado de BRASIL (2002) ${ }^{\mathrm{c}}$ e RDC n ${ }^{\mathrm{o}} 12$ (BRASIL,

$$
\text { 2001) }{ }^{\mathrm{d}} \text {. }
$$

As etapas de desenforme e embalagem são Pontos Críticos de Controle, pois o desenforme e acondicionamento são as últimas etapas do processo de fabricação do bombom, por isso não deve haver contaminação. É importante que o recebimento e estocagem da embalagem seja em local adequado até ser levada a linha de produção do bombom. 


\section{Armazenamento e transporte}

Quadro 3. Pontos Críticos de Controle para etapa de armazenamento e transporte na produção de bombons artesanais em Campo Grande - MS.

\begin{tabular}{|c|c|}
\hline $\begin{array}{l}\text { Perigo para qualidade e } \\
\text { segurança }\end{array}$ & $\begin{array}{l}\text { Biológico: multiplicação de microrganismos patogênicos }{ }^{\text {a }} \\
\text { Físicos: insetos, poeira, materiais estranhos }{ }^{a}\end{array}$ \\
\hline Medidas preventivas & $\begin{array}{l}\text { Controle de tempo/temperatura para evitar proliferação de } \\
\text { microrganismos que aumente o risco }{ }^{b} \\
\text { Condições de armazenamento adequadas (condições higiênicas) }{ }^{b} \\
\text { Limpeza e sanitização dos equipamentos e ambiente (evitar } \\
\text { recontaminação pós processo térmico) }{ }^{b} \\
\text { Sistemas adequados de limpeza e sanitização após processamento }{ }^{b} \\
\text { Uso de telas protetoras nas janelas e portas }{ }^{b} \\
\text { Retirada de materiais estranhos da área de armazenamento e/ou } \\
\text { transporte }^{b}\end{array}$ \\
\hline Risco & Médio a $^{\text {a }}$ \\
\hline Severidade & Alto $^{a}$ \\
\hline Limite crítico & $\begin{array}{l}\text { Coliformes a } 45^{\circ} \mathrm{C} \text { : } 10 \text { UFC/g de amostra }{ }^{\mathrm{d}} \\
\text { Staphylococcus aureus (Estaf. coag. Positiva): } 5 \times 10^{2} \text { UFC/g de } \\
\text { amostra }^{\mathrm{b}} \\
\text { Salmonella sp: ausência em } 25 \mathrm{~g} \text { de amostra }{ }^{\mathrm{d}}\end{array}$ \\
\hline Monitoramento & $\begin{array}{l}\text { O quê? Condições de armazenamento e transporte }{ }^{a} \\
\text { Como? Limpeza e sanitização }{ }^{a} \\
\text { Quando? A cada lote recebido } \\
\text { Quem? Funcionário responsável pelo recebimento do lote de chocolate } \\
\text { a }\end{array}$ \\
\hline Ação corretiva & Não aceitar o lote fora do limite crítico de segurança ${ }^{a}$ \\
\hline Verificação & $\begin{array}{l}\text { Verificar a veracidade dos laudos, realizando testes microbiológicos } \\
\text { semanais a }\end{array}$ \\
\hline Registro & $\begin{array}{l}\text { Registrar os laudos recebidos e as análises de verificação com } \\
\text { assinatura do responsável e data de recebimento a }\end{array}$ \\
\hline
\end{tabular}

Fonte: Própria (2020) ${ }^{\mathrm{a}}$, adaptado de SEBRAE (2000) ${ }^{\mathrm{b}}$, adaptado de BRASIL (2002) ${ }^{\mathrm{c}}$ e $\mathrm{RDC}^{\mathrm{o}} 12$ (BRASIL, 2001) d.

Essa etapa é um ponto crítico de controle, pois não há nenhuma etapa posterior que elimine os perigos, caso estejam presentes, assim o armazenamento do bombom elaborado deve ser monitorado. A cada compra de lote de chocolate para cobertura, deverá ser exigido da empresa fornecedora laudos garantindo a segurança microbiológica. É importante que o produto final fique armazenado em local adequado até ser levado para o transporte, e controle de temperatura, preferencialmente com transporte refrigerado.

As condições de embalamento e armazenamento são importantes na manutenção das 
características organolépticas, sobretudo aromas e aparência. Quando o chocolate é exposto a altas temperaturas durante o armazenamento pode haver alteração em sua aparência, cor e brilho (DIOGO et al., 2015)

Quanto aos riscos microbiológicos, pode-se relacionar a presença de Salmonella, à sanidade do produto, enquanto coliformes totais são utilizados como indicadores de higiene durante a produção, transporte e armazenamento dos produtos (TEJEDA et al., 2012). A fim de garantir a qualidade na produção e comercialização destes bombons, além da saúde do consumidor, é necessária a padronização do processo de fabricação caseira e um adequado controle higiênico-sanitário tanto do local de produção, quanto dos manipuladores e onde os bombons serão comercializados.

O controle do processo de fabricação de produtos alimentícios influencia diretamente em sua qualidade final. Para se obter excelência, todo o processo deve ser analisado, controlado e monitorado para que os requisitos desejados e especificações técnicas sejam atendidos (QUINTINO; RODOLPHO, 2018).

\section{Conclusões}

A qualidade e segurança na produção dos bombons artesanais se iniciam com as Boas Práticas de Fabricação que necessitam dos Procedimentos Operacionais Padrão para contribuir na manutenção das condições higiênico-sanitárias adequadas à produção de alimentos, o que aumentaria a porcentagem de conformidade.

Os Pontos Críticos de Controle detectados na observação in loco para a segurança dos consumidores de bombom artesanal foram a embalagem, o armazenamento e o transporte. Devido à falta de tratamento térmico do chocolate utilizado, a etapa de resfriamento é considerada um ponto crítico de controle para qualidade, assim como a embalagem, por ser a última etapa do processo.

É necessária a padronização do processo de fabricação caseira e um adequado controle higiênico-sanitário do local de produção, dos manipuladores e dos pontos de comercialização dos bombons, garantindo a qualidade e segurança do produto, tanto para o consumidor quanto para o produtor. Mesmo apresentando baixo risco sanitário, a produção de bombons artesanais deve seguir as recomendações especificadas na legislação.

\section{Referências}

BATISTA, A. P. S. A. Chocolate: sua história e principais características. Orientadora: 
Fabiana Lopes Nalon. 2008. 56 f. Dissertação (Curso de Especialização em Gastronomia e Saúde) - Centro de Excelência em Turismo, Universidade de Brasília, Brasília, 2008.

BRASIL. Ministério da Agricultura, Pecuária e Abastecimento. Portaria $\mathrm{n}^{\circ}$ 46, de 10 de fevereiro de 1998. Manual genérico para APPCC em indústrias de produtos de origem animal. Diário Oficial da União, Brasília, DF, 1998. Disponível em: https://www.defesa.agricultura.sp.gov.br/legislacoes/portaria-ma-46-de-10-02-1998,687.html. Acesso em: 29 de jul. de 2020.

BRASIL. Ministério da Saúde. Anvisa - Agência Nacional de Vigilância Sanitária. RDC n ${ }^{\circ}$ 49, de 31 de outubro de 2013. Dispõe sobre a regularização para o exercício de atividade de interesse sanitário do microempreendedor individual, do empreendimento familiar rural e do empreendimento econômico solidário e dá outras providências. Diário Oficial da União, Brasília, DF, 2013. Disponível em: http://bvsms.saude.gov.br/bvs/saudelegis/anvisa/2013/rdc 0049_31_10_2013.html. Acesso em: 24 de jul. de 2020.

BRASIL. Ministério da Saúde. Anvisa - Agência Nacional de Vigilância Sanitária. RDC n 264, de 22 de setembro de 2005. Aprova o "Regulamento Técnico para Chocolate e Produtos de Cacau". Diário Oficial da União, Brasília, DF, 2005. Disponível em: http://portal.anvisa.gov.br/documents/10181/2718376/RDC_264_2005_.pdf/081370e3-e45d454f-840a-a728ef62e3e5. Acesso em: 24 de jul. de 2020.

BRASIL. Secretaria de Vigilância Sanitária. Portaria SVS/MS nº 326, de 30 de julho de 1997. Regulamento técnico sobre as condições higiênico-sanitárias e de boas práticas de fabricação para estabelecimentos produtores/industrializadores de alimentos. Diário Oficial da União, Brasília, DF, 1997. Disponível em: http://portal.anvisa.gov.br/documents/33916/388704/Port aria\%2BSVS-MS\%2BN.\%2B326\%2Bde\%2B30\%2Bde\%2BJulho\%2Bde\%2B1997.pdf/87a1 ab03-0650-4e67-9f31-59d8be3de167. Acesso em: 29 de jul. de 2020.

BRASIL. Ministério da Saúde. Anvisa - Agência Nacional de Vigilância Sanitária. RDC n ${ }^{\circ}$ 275, de 21 de outubro de 2002. Regulamento Técnico de Procedimentos Operacionais Padronizados aplicados aos Estabelecimentos Produtores/Industrializadores de Alimentos e a Lista de Verificação das Boas Práticas de Fabricação em Estabelecimentos Produtores/Industrializadores de Alimentos. Diário Oficial da União, Brasília, DF, 2002. Disponível em: http://portal.anvisa.gov.br/documents/10181/2718376/RDC_275_2002_COM P.pdf/fce9dac0-ae57-4de2-8cf9-e286a383f254. Acesso em: 24 de jul. de 2020.

CINTRÃO, R. P. Segurança alimentar, riscos, escalas de produção - desafios para a regulação sanitária. Vigilância Sanitária em Debate: Sociedade, Ciência \& Tecnologia, v. 5, p. 3-13, 2017.

CORREA, P. F.; DE OLIVEIRA, L. B.; Aplicação das ferramentas da qualidade na solução de problemas de contaminação em uma fábrica de chocolate. Revista de Engenharia e Pesquisa Aplicada, v. 2, p. 86-101, 2017.

DE OLIVEIRA, A. M. C.; SOUSA, P. V.; ALVES, A. A. S.; MEDEIROS, S. R. A.; MENDONÇA, M. J. N. Adequação de serviços de alimentação às boas práticas de fabricação. Conexões-Ciência e Tecnologia, v. 14, p. 30-36, 2020.

DIOGO, F. M. J. Desenvolvimento de um Bombom de Chocolate com recheio de queijo 
fundido e compota de fruta. Orientadores: Rui Alves e Carla Barbosa, 2015. $131 \mathrm{f}$. Dissertação (Mestrado em Empreendedorismo e Inovação na Indústria Alimentar) -Escola Superior de Tecnologia e Gestão, Instituto Politécnico de Viana Castelo, Viana do Castelo, Portugal, 2015.

FIGUEIREDO, V. F.; COSTA NETO, P. L. O. Implantação do HACCP na indústria de alimentos. Gestão \& Produção, v. 8, p. 100-11, 2001.

GIL, A. C. Como elaborar projetos de pesquisa. 5. ed. São Paulo: Atlas, 2008.

SEBRAE. Guia para elaboração do plano APPCC: geral. 2. ed. Brasília, SENAI/DN, 2000. $301 \mathrm{p}$.

LOVATTI, R. C. C. Gestão da qualidade em alimentos: uma abordagem prática. Higiene Alimentar, v. 18, p. 26-31, 2004.

LUBAS, C. C. S.; CÂNDIDO, C. J.; SOUZA, S. V. S.; GUIMARÃES, R. C. A. Qualidade nutricional de barras de chocolate adicionadas de castanhas de baru. Multitemas, v. 21, p. 181-192, 2016.

ORGANIZAÇÃO PAN-AMERICANA DA SAÚDE - OPAS. A atenção à saúde coordenada pela APS: construindo as redes de atenção no SUS - Contribuições para o debate. Brasília: OPAS, 2011.

PINTO, C. de S. Elaboração e implementação do sistema de análise de perigos e pontos críticos de controle em linha de chocolate ao leite. Orientadora: Heloísa Theodoro, 2017. 63 f. Trabalho de conclusão de curso (Nutrição) - Campus da Região das Hortência, Universidade de Caxias do Sul, Rio Grande do Sul, 2017.

QUINTINO, S. da S.; RODOLPHO, D.; Um estudo sobre a importância do APPCC - Análise de Perigos e Pontos Críticos de Controle - na indústria de alimentos. Revista Interface Tecnológica. v. 15, p. 196-207, 2018.

RIBEIRO-FURTINI, L. L.; ABREU, L. R. Utilização de APPCC na indústria de alimentos. Ciência e Agrotecnologia, v. 30, p. 358-363, 2006.

ROSA, P. T. Implantação do Manual de Boas Práticas de Manipulação em cozinha pedagógica de uma instituição de ensino na cidade de Campo Mourão - PR. Orientadora: Tanatiana Ferreira Guelbert, 2015. 176 f. Trabalho de Conclusão de Curso (Curso Superior de Tecnologia de Alimentos) - Departamento Acadêmico de Alimentos, Universidade Tecnológica Federal do Paraná, Campo Mourão, 2015.

SALGADO, T. M. V.; ALCÂNTARA, L. O.; CARVALHO, M. S. M. APPCC: uma ferramenta da gestão da segurança de alimentos. Alimentos: Ciência, Tecnologia e Meio Ambiente, v. 1, p. $90-107,2020$.

SILVA JUNIOR, E. A. Manual de controle higiênico-sanitário em alimentos. 5. ed. São Paulo: Varela, 2002. 350 p.

SOUSA, C. L.; LOURENÇO, L. F. H.; FRANCÊS, J. M. de O.; SOARES, Y. P. P.; 
ARAÚJO, E. A. F.; PENA, R. da S. Avaliação microbiológica, físico-química e das condições de fabricação de bombom de chocolate com recheio de frutas. Alimentos e Nutrição, v. 21, p. 305-310, 2010.

TEJADA, T. S.; DIAS, P. A.; CONCEIÇÃO, R. C. S. TIMM, C. D. Micro-organismos patogênicos e deteriorantes em chocolate artesanal ao leite. Revista do Instituto Adolfo Lutz (impresso), v. 71, p. 178-81. 2012. 